\title{
Administering Copper Blocks CA1 Neuron Hyper-Excitability in Rat Hippocampal Slices*
}

\author{
Juan Leiva ${ }^{\#}$, Mario Palestini, Claudio Infante \\ Facultad de Medicina, Instituto de Ciencias, Biomédicas, Universidad de Chile, Santiago, Chile

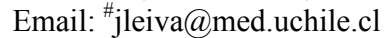

Received July 2, 2013; revised August 2, 2013; accepted August 15, 2013

Copyright (C) 2013 Juan Leiva et al. This is an open access article distributed under the Creative Commons Attribution License, which permits unrestricted use, distribution, and reproduction in any medium, provided the original work is properly cited.

\begin{abstract}
The aim of this study was to determine the capacity of copper to modify synaptic hyperexcitability generated by penicillin G. This epileptogenic drug was studied with CA1 neurons of the rat hippocampus. Hippocampal slices were extracted from adult male Wistar rats $(\mathrm{n}=16)$. The field potentials $(\mathrm{FP})$ were registered in CA1 neurons after electrical stimulation from the stratum radiatum. The mean voltage and duration of FP were measured during control, penicillin $\mathrm{G}$, copper and washout stages. Copper $(100 \mu \mathrm{M})$ significantly decreased mean FP voltage compared to the control and penicillin stages. However, during the washout stage, the mean FP voltage was significantly higher than in the penicillin stage. Regarding the FP duration, $100 \mu \mathrm{M}$ of copper significantly decreased the mean FP during the penicillin stage. After the washing stage, the mean FP lasted significantly longer. Thus, administering copper modified CA1 synapses by blocking hippocampal neuronal excitability was generated by the epileptic agent.
\end{abstract}

Keywords: Copper; Field Potential (FP); Hippocampus; Penicillin G

\section{Introduction}

Copper is an integral component of several proteins and as a trace element is a necessary co-factor for diverse enzymatic reactions [1]. Copper can react with proteins by bonding to thiolate, amino and carboxylic groups present in macromolecules. Copper is associated with cytochrome oxidase, metallothionein, superoxide dismutase, dopamine $\beta$ hydroxylase, tyrosinase, lysyl oxidase activities and coagulation factors V and VIII [2-4].

Recent studies have considered the role of copper in neurodegenerative diseases such as Wilson's, Menkes, Alzheimer's, Parkinson's, amyotrophic lateral sclerosis and prion disease [5-9].

According to experimental results, $100 \mu \mathrm{M}$ of copper in the rat cortical neurons is capable of modulating neuronal activity $[10,11]$. We have recently shown that copper sulfate at concentration as low as $10 \mu \mathrm{M}$ can partially reduce neuronal field potentials (FP) [12] and suppress LTP (a form of persistent synaptic voltage increase after a high rate of stimulus) observed in CA1 neurons in rat hippocampal slices [13]. In the same direction, it has been described that LTP is not induced in the CA1 neurons of rats that drank water with copper sulfate (8 to 12

${ }^{*}$ Conflict of interest statement: The authors have no conflict of interest.

${ }^{\#}$ Corresponding author. $\mathrm{mg} / \mathrm{Kg} /$ day) for 30 days. Under similar experimental conditions, the threshold to evoke the FP clearly increased $[14,15]$. On the other hand, rats with intra-peritoneal (i.p.) administration of copper sulfate $(1 \mathrm{mg} / \mathrm{kg} /$ day $)$ for 30 days did not exhibit LTP, at the CA1. However, they were successful in performing the Morris water test (16).

Studies by other authors, as well as those of our group, have strengthened the idea that copper can exert an inhibitory effect on the neuronal transmission. Taking into account the inhibitory role of copper in CA1 synaptic activity, the current study was conducted to determine the capacity of copper to modify synaptic hyperexcitability generated by penicillin $\mathrm{G}$, a drug that induces epileptogenic activity [17].

\section{Methods}

Adult male Wistar rats $(\mathrm{n}=16)$ weighing between 150 and $250 \mathrm{~g}$, with a mean age of $6.7 \pm 1$ weeks, were maintained at $22^{\circ} \mathrm{C} \pm 1{ }^{\circ} \mathrm{C}$ with a light/dark cycle of $12 / 12$ $\mathrm{h}$. Experiments were conducted in accordance with the Guide for the Care and Use of Laboratory Animals, published by the National Institutes of Health. The experimental protocol was approved by the Bioethical Committee of the Institute of Biomedical Sciences, Faculty of Medicine of the Universidad de Chile. 
The animals were deeply anesthetized with ether and decapitated with a Stoelting guillotine once tactile leg and corneal reflexes were no longer apparent. The brain was rapidly removed under a continuous cold KrebsRinger (K-R) drip and then submerged for a short period in K-R. The hippocampus was removed from the hemibrain, and was cut into $400 \mu \mathrm{M}$ coronal slices [18] with a McIlwain Tissue Chopper 5 (Mickle Laboratory Engineering, Surrey, UK). The slices were submerged in an incubation chamber for $1 \mathrm{~h}$, and then transferred to the immersion register chamber with continuous $\mathrm{K}-\mathrm{R}$ perfusion at $31^{\circ} \mathrm{C} \pm 1{ }^{\circ} \mathrm{C}$.

The K-R solution was composed of (in $\mathrm{mM}$ ) $\mathrm{NaCl}$ 124.0, $\mathrm{KCl} 5.0, \mathrm{KH}_{2} \mathrm{PO}_{4} 1.25, \mathrm{MgSO}_{4}+7 \mathrm{H}_{2} \mathrm{O} 2.0, \mathrm{CaCl}_{2}$ 2.0, $\mathrm{NaHCO}_{3} 26.0$ and glucose 10 at $\mathrm{pH} 7.4$, solution was previously bubbled with carbooxigen $\left(95 \% \mathrm{O}_{2}\right.$ and $5 \%$ $\mathrm{CO}_{2}$ ). The perfusion system provided a continuous flow of 2 to $3 \mathrm{ml} / \mathrm{min}$.

\subsection{Neural Registration in Vitro}

Hippocampal slices were placed in an immersion chamber with a nylon net on the bottom. The stratum radiatum was stimulated with bipolar tungsten electrodes through a Digitimer Trigger Generator DG2 connected to an Isolated Stimulator (model DS2A) Single pulses of $0.5-6.0$ volt stimulus were employed at $10 \mathrm{~s}$ intervals. The pulses had a duration of $0.30 \mathrm{~ms}$, with a frequency of $0.1-0.01$ $\mathrm{Hz}$ at twice the threshold. The field excitatory postsynaptic potentials were recorded (fEPSP or FP) with glass micropipettes filled with K-R with 1 to $1.5 \mathrm{M} \Omega$ of impedance. The microelectrodes were visually positioned in CA1 with the assistance of a binocular magnifying glass (Carl Zeiss). A hydraulic micromanipulator allowed us to move the micropipette through the depth of the slice. Neural activity was captured with an amplifier (BioLogic VF180), which displayed the signal in an oscilloscope (Hitachi VC-6020). A recording was made simultaneously with a tape recorder (SONY.DTC.59 E.S) for offline analysis. Analog-to-digital data conversion was done using a Cambridge Electronic Device (CED). Digitized data were averaged using a program (SIGAVG) on a Pentium microcomputer.

\subsection{Experimental Procedure}

After defining the FP under control conditions, 500 $1500 \mathrm{UI} / \mathrm{ml}$ of penicillin $\mathrm{G}$ was administered for 7 - 10 min. This period is termed the penicillin stage. The slide was then perfused with $100 \mu \mathrm{M}$ of copper sulphate, for 7 - $10 \mathrm{~min}$, which constitutes the copper stage. Finally, the preparation was washed out with K-R for 30 to 120 minutes, until reaching the initial control FP $(n=15)$. The recording period and the stimulation modality were similar to those previously described (16). We analyzed only the slices that showed stable responses over the four stages.

\subsection{Statistical Analysis}

The responses evoked in each stage were monitored on the oscilloscope and signals sent to an analog-to-digital data conversion device (Cambridge Electronic Design). Digitalized data were analyzed with an averaging program (SIGAVEG), and a one-way ANOVA and Newman-Keuls $t$ tests were applied to identify significant differences in voltage and the duration of FP responses using the program Prisma (www.GraftPath.com). A value of $\mathrm{P}<0.05$ was considered statistically significant.

\section{Results}

\subsection{Modification of the Mean FP Voltage during the Penicillin G, Copper and Wash Periods}

Electrical stimulation of the stratum radiatum at twice threshold resulted in a stable synaptic responses in pyramidal CA1 neurons. FP responses were characterized at least four positive and negative inflections as a result of synaptic activity from distinct afferent collaterals, their latencies being 4, 7, 9 and $12 \mathrm{~ms}$, respectively. For comparison, the amplitude of the first inflection was considered the basal response and presented a mean amplitude of $10.87 \pm 1.42 \mathrm{mV}$. Penicillin perfusion (500 IU) provoked an increase of the basal FP, which reached a mean value of $16.6 \pm 1.44 \mathrm{mV}$, which was clearly higher than the FP observed during the control stage $(\mathrm{F}(3,56)=$ 932.9, $\mathrm{q}=14.14, \mathrm{P}<0.001)$. Eight minutes later copper sulfate perfusion at $100 \mu \mathrm{M}$, reduced the mean FP amplitude to $2.9 \pm 0.7 \mathrm{mV}$. This value was significantly lower than the FP during the penicillin and control stage $(\mathrm{F}(3,56)=932.9, \mathrm{q}=33.5, \mathrm{P}<0.001)$ and $(\mathrm{F}(3,56)=$ 932.9, $\mathrm{q}=19.4, \mathrm{P}<0.001)$, respectively. A subsequent K-R washout for 60 - 120 minutes increased the mean FP to $32.54 \pm 2.35 \mathrm{mV}$. This value was clearly higher than the FP observed during the control stage $(\mathrm{F}(3,56)=$ 932.8, $\mathrm{q}=52.8, \mathrm{P}<0.001)$; copper stage $(\mathrm{F}(3,56)=$ 932.9, $\mathrm{q}=72.2, \mathrm{P}<0.001)$, and after the penicillin stage $(F(3,56)=932.8, q=38.7, P<0.001)$, see Figure 1(A).

\subsection{Mean FP Duration during the Penicillin G, Copper and Washout Periods}

The FP duration was defined as the interval between the beginning of the stimulus and the end of the global FP response. Synaptic FP responses in pyramidal CA1 neurons presented four stable inflections with a mean duration of $22.6 \pm 1.9 \mathrm{~ms}$. Penicillin G perfusion with $500 \mathrm{IU}$ increased the mean FP duration to $33.31 \pm 3.2 \mathrm{~ms}$, which 

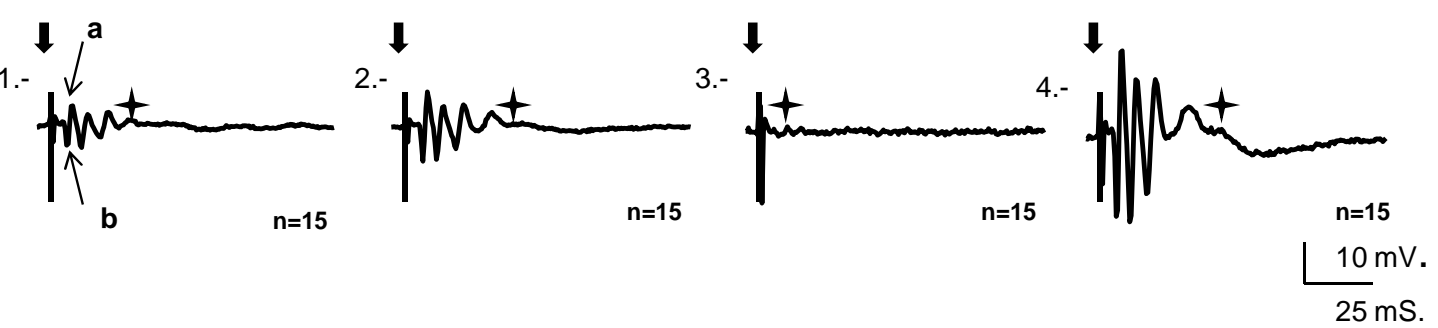

A
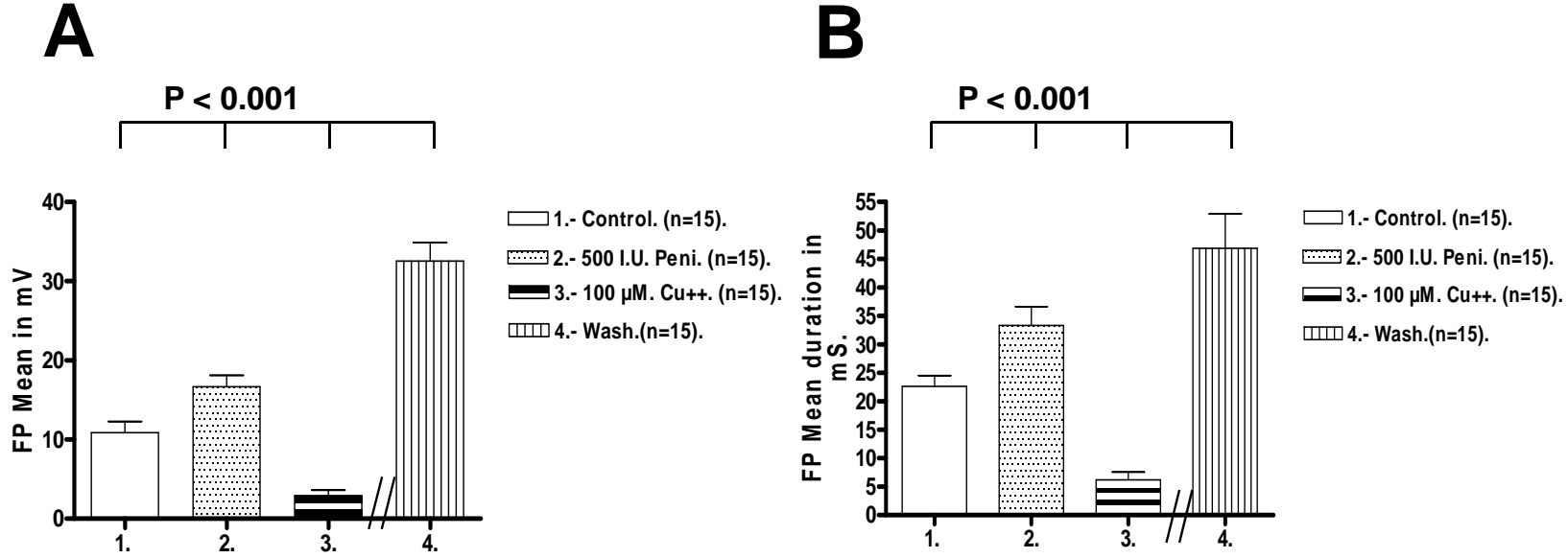

Figure 1. Top: The recordings show the mean FP voltage responses obtained from pyramidal CA1 neurons in rat hippocampal slices $(n=15)$ using penicillin $G$ as an epileptic agent. The responses were obtained during four periods: 1) Control stage; 2) Penicillin G (500 UI) stage for 8 - $10 \mathrm{~min}$; 3) Copper sulfate (100 $\mu \mathrm{M})$, stage for eight to ten min; 4) Wash stage. The recordings for the wash stage were made 120 min after this period began. During each stage, we stimulated the stratum radiatum at double the threshold to induce FP responses. The broad arrow indicates the time of stimulation and the start of FP. The star marks the end of responses. Calibrations are shown. Lower Left. (A) The graph shows the mean FP voltage $(n=15)$ measured in the first inflection of the response (EPSP), indicated by the narrow arrows (a, b) in recording 1 , above. There were significant differences among the four recording stages in mean voltage responses, as indicated by a one-way ANOVA followed by a Newman-Keuls statistical test. Lower Right. (B) The graph shows the mean duration of the FP (n $=15$ ) measured during the four stages described above. There were significant differences in mean FP duration, as indicated by a one-way ANOVA followed by a Newman-Keuls statistical test.

was significantly higher than the FP observed during the control stage $(\mathrm{F}(3,56)=339.3, \mathrm{q}=11.4, \mathrm{P}<0.001)$. This increase is considered indicative of neuronal hyperexcitability because new excitatory synaptic activity can increase the FP duration. [19]. Copper sulfate at $100 \mu \mathrm{M}$, perfused for eight to ten min decreased the mean FP duration to $6.2 \pm 1.4 \mathrm{~ms}$, which was significant compared to the penicillin stage $(\mathrm{F}(3,56)=339.3, \mathrm{q}=29.1, \mathrm{P}<$ 0.001). The mean FP duration during the copper stage was also significantly shorter than the control stage $(\mathrm{F}(3$, $56)=339.3, \mathrm{q}=17.6, \mathrm{P}<0.001)$. Recordings obtained 100 min after the beginning of the washout stage had a mean FP duration of $46.9 \pm 6.0 \mathrm{~ms}$, which was significantly higher than the control stage $(\mathrm{F}(3,56)=339.3, \mathrm{q}=$ $25.9, \mathrm{P}<0.001)$, penicillin stage $(\mathrm{F}(3,56)=339.3, \mathrm{q}=$ $14.5, \mathrm{P}<0.001)$ and copper stage $(\mathrm{F}(3,56)=339.3, \mathrm{q}=$ 43.6, $\mathrm{P}<0.001)$, See Figure 1(B).

\section{Discussion}

The principal result of this work indicates that copper sulfate in physiological concentrations significantly re- duces the hyperactivity of CA1 neurons, defined by changes in both the amplitude and duration of the FP. This phenomenon occurred when a hippocampal slice was perfused with penicillin $G$, a recognized epileptogenic substance. Before penicillin perfusion, copper reduced the hipocampal FP response, confirming previous results $[12,13,15,16]$. As described before, copper perfused before tetanic stimulation prevented LTP generation in CA1 neurons [13]. A similar effect has been obtained with 5-amino-phosphovalerate (a NMDA receptor antagonist) [14]. However, if 5-amino-phosphovalerate is perfused after settling down the LTP; this effect was not observed. This result suggests that the NMDA receptor antagonist did not block the biochemical machinery that supports long-term LTP consolidation. Instead, copper perfusion in different concentrations temporarily blocked FP response before and after tetanic stimulation $[13,14]$. 5-amino-phosphovalerate has a selective inhibitory effect on NMDA receptors, while copper exerts a non-selective effect. There is evidence that copper blocks AMPA and NMDA receptors by interfering with the NR2A subunit, 
NMDA and AMPA receptor blocking by copper would prevent LTP generation [20-23]. The NMDA receptor NR1/NR2A sub-units are responsible for kinetic and pharmacological interactions with other subunits $[24,25]$; LTP blocking by copper probably also includes interference of AMPA receptors $[21,22]$. As has been described, copper inhibits AMPA currents, thus decreasing synaptic activity, including typical miniature synaptic currents [26]. It is probable that similar phenomena occurred under our experimental conditions.

In the present study, 500 I.U. of penicillin G significantly increased the voltage and duration of FP compared to the FP control. Although there is no definitive explanation for penicillin-induced hyperexcitability, it is thought that penicillin interferes with GABA-mediated inhibition [17-29]. A similar mechanism has been proposed for another epileptogenic agent, like Pentylentetrazol (PTZ) [30]. In our results penicillin-induced hyperexcitability was significantly attenuated by copper, but after the washout period the hyperexcitability response was significantly higher than those initially generated by penicillin G. A possible explanation could be in an increase of NMDA and/or AMPA receptor expression as a result of the partial blocking of the synaptic traffic through these receptors promoted by copper. Alternatively, copper could produce changes in the affinity of the AMPA receptors. [26]. The effects of copper on the FP could be related to temporal blocking of AMPA receptors; which could result in upregulation of those receptors. Accordingly, an important link has been found between AMPA and copper. In fact, it has been demonstrated that copper produces biphasic changes in neurotransmission. When copper is acutely applied to the synaptic cleft, it blocks neurotransmission, but when it is applied for $3 \mathrm{~h}$ to the hippocampal neurons it mainly increases the frequency and amplitude of evoked AMPAergic current, which is considered dependent on the concentration of copper [26]. Another possibility is that copper interacts with the GABA receptor, replacing zinc, which is present in high concentrations in structures of the limbic system including the hippocampus [31-34]. In this regard, it has been reported that synaptic release of zinc can interact with ion channels and receptors, including the AMPA, NMDA and GABA receptors, reducing the threshold response [31-40]. Like copper, zinc inhibits LTP, suggesting that the two trace metals share the same targets [41].

On the other hand, there is an evidence of chronic copper deregulation associated with neurodegenerative and chronic diseases [5-9], including epilepsy [42]. In our study, however, the effect of acute copper administration is in contrast with the high levels of copper present in the plasma of epileptic patients [42,43].

The result of the acute copper administration and its subsequent discontinuity can be related to the over-expression of glutamatergic receptors as a consequence of temporal blocking of the glutamatergic synapses. However, we cannot rule out that copper can also interact with other proteins related to neuronal transmission. In fact, copper can also interact with channel proteins; for instance, with $\mathrm{K}^{+}$and $\mathrm{Na}^{+}$or $\mathrm{Ca}^{++}$channels. It has been demonstrated that copper reversibly inhibits $\mathrm{BK}$ and shaker $\mathrm{K}^{+}$channels in micro molar concentration [44]. As well, It has been described that administration of nano$\mathrm{Cu}$ in hippocampal CA1 inhibits amplitude of $\mathrm{Na}^{+}$depolarizing currents [45], additionally copper has a high affinity for the Ca v 3.2 T-type calcium channels, stabilizing the closed conformation of the voltage-sensor and thereby inhibits channel opening [46]; moreover, $\mathrm{Cu}$ can also block $\mathrm{Ca}$ currents in high-voltage activated $\mathrm{Ca}$ channels [47]. Therefore, acute excitatory blocking can result from NMDA receptor blocking and/or blocking of depolarization currents at the hippocampus synaptic circuitry. These two general mechanisms may be involved in the up regulation of the excitatory transmission. Previous results and those that indicate a significant reduction of copper concentration in rat brain cells after administration of single and/or repeated Pentylentetrasol (PTZ) [48] suggest that chronic reductions in copper levels can facilitate the propensity to epileptic diseases; while increasing the copper concentration could attenuate this effect. If this is the case, copper could be used as an antiepileptic substance. However, further experimental studies are necessary before any final conclusions can be reached.

\section{REFERENCES}

[1] M. Olivares and R. Uauy, "Copper as an Essential Nutrient," The American Journal of Clinical Nutrition, Vol. 63, No. 5, 1996, pp. 791S-796S.

[2] R. J. Cousins, "Metal Elements and Gene Expression," Annual Review of Nutrition, Vol. 14, 1994, pp. 449-469. doi:10.1146/annurev.nu.14.070194.002313

[3] M. C. Linder and M. Hazegh-Azam, "Copper Biochemistry and Molecular Biology," The American Journal of Clinical Nutrition, Vol. 63, No. 5, 1996, pp. 797S-811S.

[4] J. T., Pennington and D. H. Calloway, "Copper Content of Food," Journal of the American Dietetic Association, Vol. 63, 1974, pp. 145-173.

[5] G. J. Brewer, “Copper Excess, Zinc Deficiency, and Cognition Loss in Alzheimer's Disease," Biofactors, Vol. 38, No. 2, 2012, pp. 107-113. doi:10.1002/biof.1005

[6] L. Varela-Nallar, E. M. Toledo, M. A. Chacón and N. Inestrosa, "The Functional Links between Prion Protein and Copper," Biological Research, Vol. 39, No. 1, 2006 , pp. 39-44. doi:10.4067/S0716-97602006000100005

[7] M. A. Chacón, M. I. Barría, R. Lorca, J. P. HuidobroToro and N. C. Inestrosa, "A Human Prion Protein Pep- 
tide (PrP59-91) Protects against Copper Neurotoxicity," Molecular Psychiatry, Vol. 8, No. 10, 2003, pp. 853-862. doi:10.1038/sj.mp.4001400

[8] D. J. Waggoner, T. B. Bartnikas and J. D. Gitlin, "The Role of Copper in Neurodegenerative Disease," Neurobiology of Disease, Vol. 6, No. 4, 1999, pp. 221-230. doi:10.1006/nbdi.1999.0250

[9] P. Zatta and A. Frank, "Copper Deficiency and Neurological Disorders in Man and Animals," Brain Research Reviews, Vol. 54, No. 2, 2007, pp. 19-33. doi:10.1016/j.brainresrev.2006.10.001

[10] D. E. Hartter and A. Bernea, "Evidence for Release of Copper in the Brain: Depolarization-Induced Release of Newly Taken up 67 Copper," Synapse, Vol. 2, No. 2, 1988, pp. 412-415. doi:10.1002/syn.890020408

[11] J. Kardos, I. Kovacs, F. Hajos, M. Kalman and M. Simoyi, "Nerve Ending from Rat Brain Tissue Releases Copper upon Depolarization. A Possible Role in Regulating Neuronal Excitability," Neuroscience Letters, Vol. 103, No. 2, 1989, pp. 139-144. doi:10.1016/0304-3940(89)90565-X

[12] J. Leiva, M. Palestini, M. Tetas and J. López, "Copper Sensitivity in Dorsal Hippocampus Slices," Archives Italiennes de Biologie, Vol. 138, No. 2, 2000, pp. 175-184.

[13] J. Leiva, M. Palestini and P. Gaete, "Copper Interaction on the Long-Term Potentiation," Archives Italiennes de Biologie, Vol. 141, No. 4, 2003, pp.149-155.

[14] Y. Doroulee, H. Yanovky and H. Haas, "Suppression of Long-Term Potentiation in Hippocampal Slices by Copper,” Hippocampus, Vol. 7, No. 6, 1997, pp. 666-669. doi:10.1002/(SICI)1098-1063(1997)7:6<666::AID-HIPO 8>3.0.CO;2-C

[15] A. Goldschmith, C. Infante, J. Leiva, E. Motles and M. Palestini, "Interference of Chronically Ingested Copper in Long-Term Potentiation (LTP) of Rat Hippocampus," Brain Research, Vol. 1056, No. 2, 2005, pp. 176-182. doi:10.1016/j.brainres.2005.07.030

[16] J. Leiva, M. Palestini, C. Infante, A. Goldschmith and E. Motles, "Copper Suppresses Hippocampus LTP in the Rat, But Does Not Alter Learning or Memory in the Morris Water Maze," Brain Research, Vol. 1256, No. 23, 2009, pp. 69-75. doi:10.1016/j.brainres.2008.12.041

[17] A. E. Weiker and H. C. Johnson, "Convulsive Factor in Commercial Penicillin," Archives of Surgery, Vol. 50. No. 2, 1945, pp. 69-73. doi:10.1001/archsurg.1945.01230030074003

[18] R. Dingledine and L. Gjerstand, "Reduced Inhibition during Epileptiform Activity in the in Vitro Hippocampal Slices," The Journal of Physiology (London), Vol. 305, 1980, pp. 297-313.

[19] N. F. Santos, R. H. Marquez, L. Correia, R. SinnigagliaCoimbra, L. Calderazzo, E. R. G. Sanabria and E. A. Cavalheiro, "Long-Term Consequences of Mutiple Pilocarpine-Induced Status Epilepticus during Early Life," Congreso Latinoamericano de Epilepsia, OMS/OPSILAEIBE, Santiago, 2000, pp. 200-206.

[20] E. R. Kandel, T. M., Schwar and T. M. Jessell, "Neurociencia y Conducta, Chap. 36," In: E. R. Kandel, T. M., Schwar and T. M. Jessell, Eds., Mecanismos Celulares del Aprendizaje y la Memoria, Prentice Hall, Madrid, 1997, pp. 730-738.

[21] S. J. Martin, P. D. Grimwood and R. G. M. Morris, "Synaptic Plasticity and Memory: An Evaluation of Hypothesis," Annual Review of Neuroscience, Vol. 23, 2000, pp. 649-777. doi:10.1146/annurev.neuro.23.1.649

[22] P. Revest and A. Longstaff, "Molecular Neuroscience, Chap. 8," In: P. Revest and A. Longstaff, Eds., Mechanism of Plasticity, Springer-Verlag, Inc., New York, 1998, pp. 151-190.

[23] A. I. Bush, "The Metallobiology of Alzheimer's Disease," Trends in Neurosciences, Vol. 26, No. 4, 2003, pp. 207-214. doi:10.1016/S0166-2236(03)00067-5

[24] B. Van Zundert, A. Yoshii and M. Constantine-Patton, "Receptor Compart-Mentalization and Trafficking at Glutamate Synapses: A Developmental Proposal," Trends in Neurosciences, Vol. 27, No. 7, 2004, pp. 428-436. doi:10.1016/j.tins.2004.05.010

[25] K. Erreger, Sh. M. Dravid, T. G. Banke, D. J. A. Wyllie and S. F. Traynelis, "Subunit-Specific Gating Control Rat NR1/NR2A and NR1/NR2B NMDA Channel Kinetics and Synaptic Signaling Profiles," The Journal of Physiology, Vol. 563, No. 2, 2005, pp. 345-358. doi:10.1113/jphysiol.2004.080028

[26] Ch. Peters, B. Muñoz, F. J. Sepúlveda, J. Urrutia, M. Quiroz, S. Luza, G. V. De Ferrari, L. G. Aguayo and C. Opazo, "Biphasic Effects of Copper on Neurotransmission in Rat Hippocampal Neurons," Journal of Neurochemistry, Vol. 119, No. 1, 2011, pp. 78-88. doi:10.1111/j.1471-4159.2011.07417.x

[27] G. F. Ayala and C. Vasconcelos, "Penicillin as an Epileptogenic Agent: Its Effects on an Isolated Neuron," Science, Vol. 167, No. 3922, 1970, pp. 1257-1260. doi:10.1126/science.167.3922.1257

[28] R. K. S. Wong and D. A. Prince, "Dendritic Mechanisms Underlaying Penicillin-Induced Epileptiform Activity," Science, Vol. 204, No. 4398, 1979, pp. 1228-1231. doi:10.1126/science. 451569

[29] J. Davenport, P. C. Schwindt and W. E. Crill, "Epileptogenic Doses of Penicillin Do Not Reduce a Monosynaptic GABA-Mediated Post-Synaptic Inhibition in the Intact Anesthetized Cat," Experimental Neurology, Vol. 65, No. 3, 1979, pp. 552-572. doi:10.1016/0014-4886(79)90044-X

[30] R. L. McDonald and J. L. Barker, "Pentylenetetrazole and Penicillin Are Selective Antagonists of GABA-Mediated Post-Synaptic Inhibition in Cultured Mammalian Neurons," Nature, Vol. 267, No. 5613, 1977, pp. 720-721. doi: $10.1038 / 267720 \mathrm{a} 0$

[31] C. J. Frederickson, "Neurobiology of Zinc and Zinc-Containing Neurons," International Review of Neurobiology. Vol. 31, 1989, pp. 145-238. doi:10.1016/S0074-7742(08)60279-2

[32] C. J. Frederickson and G. Danscher, "Zinc-Containing Neurons in Hippocampus and Related CNS Structures," Progress in Brain Research, Vol. 83, 1990, pp. 71-84. doi:10.1016/S0079-6123(08)61242-X

[33] C. J. Frederickson, G. A. Howell, M. D. Haigh and G. 
Danscher, "Zinc Containing Fiber Systems in the Cochlear Nuclei of the Rat and Mouse," Hearing Research, Vol. 36, No. 2-3, 1988, pp. 203-211.

[34] V. Bancila, I. Nokonenko, Y. Dunant and A. Bloc, "Zinc Inhibits Glutamate Release via Activation of Pre-Synaptic K Channels and Reduces Ischaemic Damage in Rat Hippocampus," Journal of Neurochemistry, Vol. 90, No. 5, 2004, pp. 1243-1250. doi:10.1111/j.1471-4159.2004.02587.x

[35] N. L. Harrison and S. J. Gibbsons, "Zn: An Endogenous Modulator of Ligand- and Voltage-Gated Ion Channels," Journal of Neuropharmacology, Vol. 33, No. 8, 1994, pp. 935-952. doi:10.1016/0028-3908(94)90152-X

[36] M. Horning and P. Q. Trombley, "Zinc and Copper Influence Excitability of Rat Olfactory Bulb Neurons by Multiple Mechanisms," Journal of Neurophysiology, Vol. 86, No. 4, 2001, pp. 1652-1660.

[37] T. G. Smart, X. Xie and B. J. Krishek, "Modulation of Inhibitory and Excitatory Amino Acid Receptor Ion Channels by Zinc," Progress in Neurobiology, Vol. 42, No. 3, 1994, pp. 393-441. doi:10.1016/0301-0082(94)90082-5

[38] A. Takeda, "Movement of Zinc and Its Functional Significance in the Brain," Brain Research Reviews, Vol. 34, No. 3, 2000, pp. 137-148. doi:10.1016/S0165-0173(00)00044-8

[39] A. Takeda, A. Minami, Y. Seki and N. Oku, "Inhibitory Function of Zinc against Excitation of Hippocampal Glutamatergic Neurons," Epilepsy Research, Vol. 57, No. 2-3, 2003, pp. 169-174.

[40] L. Zirpel and T. N. Parks, "Zinc Inhibition of Group I mGluR-Mediated Calcium Homeostasis in Auditory Neurons," Journal of the Association for Research in Otolaryngology, Vol. 2, No. 2, 2001, pp. 180-187.

[41] N. L. Salazar-Weber and J. P. Smith, "Copper Inhibits NMDA Receptor-Independent LTP and Modulates the Paired-Pulse Ratio after LTP in Mouse Hipocampal Slices," International Journal of Alzheimer's Disease,
Vol. 2011, 2011, Article ID: 864753.

[42] C. H. M. Brunia and G. Buyze, "Serum Copper Levels and Epilepsy," Epilepsia, Vol. 13, No. 5, 1972, pp. 621625. doi:10.1111/j.1528-1157.1972.tb04397.x

[43] R. W. Wojciak, E. Mojs, M. Stanislawska-Kubiak and W. Samborski, "The Serum Zinc, Cooper Iron and Chromium Concentrations in Epileptic Children," Epilepsy Research, Vol. 104, No. 1-2, 2013, pp. 40-44.

[44] M. Zhongming, K. Y. Wong and F. T. Horrigan, "An Extracellular $\mathrm{Cu}^{2+}$ Binding Site in the Voltage Sensor of BK and Shaker Potassium Channels," The Journal of General Physiology, Vol. 131, No. 5, 2008, pp. 483-502. doi:10.1085/jgp.200809980

[45] Z. Liu, S. Liu, G. Ren, T. Zhang and Z. Yang, "Nano-CuO Inhibited Voltage-Gate Sodium Current of Hippocampal CA1 via Reactive Oxygen Species but Independent from G-Proteins Pathway," Journal of Applied Toxicology, Vol. 31, No. 5, 2011, pp. 439-445. doi: $10.1002 /$ jat. 1611

[46] H. W. Kang, I. Vitko, S. S. Lee, E. Pérez-Reyes and J. H. Lee, "Structural Determinants of the High Affinity Extracellular Zinc Binding Site on $\mathrm{CA}_{\mathrm{v}} 3.2$ T-Type Calcium Channels," Journal of Biological Chemistry, Vol. 285, No. 5, 2010, pp. 3271-3281. doi:10.1074/jbc.M109.067660

[47] L. Castelli, F. Tanzi, V. Taglietti and J. Magistretti, " $\mathrm{Cu}^{2+}$, $\mathrm{Co}^{2+}$, and $\mathrm{Mn}^{2+}$ Modify the Gating Kinetics of HighVoltage-Activated $\mathrm{Ca}^{2+}$ Channels in Rat Paleocortical Neurons," Journal of Membrane Biology, Vol. 195, 2003, pp. 121-136.

[48] D. Sahin, G. Ilbay and N. Ates, "Changes in the Blood Brain Barrier Permeability and in the Brain Tissue Trace Element Concentrations after Single and Repeated Pentylenetetrazole-Induce Seizures in Rats," Pharmacological Research, Vol. 48, No. 1, 2003, pp. 69-73. 